Malnutrition and eye disease in Tanganyika

\author{
By D. S. McLaren, East African Institute for Medical Research, Mwanza, \\ Tanganyika
}

\title{
Vitamin A deficiency
}

Xerophthalmia and keratomalacia. Twenty years ago McKenzie (1939) drew attention to the problem of night-blindness and xerophthalmia in Morogoro, and surveys I have carried out at Mvumi, in the arid Central Province, show that keratomalacia is a not infrequent cause of blindness in very young children. During the period of more than I 8 months that I have been working in Mwanza, in association with the Government Hospital, there has been no case of xerophthalmia or keratomalacia. Near Lake Victoria green leafy vegetables are available nearly all the year round. Lake fish are readily obtained and the offal, including the liver, of most varieties is eaten. These are rich sources of carotene and vitamin A respectively, of which the contents in eleven species of lake fish and in twelve kinds of leaves have been determined in this Institute.

Bitot's spots. These are classically regarded as being signs of vitamin A deficiency, but a large study in which I participated, carried out on Ethiopian schoolchildren, showed that those with Bitot's spots did not have lower plasma vitamin A and carotenoid levels than those without them, nor did they show any impairment of dark adaptation. The surveys in Tanganyika have failed to show any higher incidence of Bitot's spots amongst schoolchildren in the Central Province area (three cases in 672 boys, and two cases in 395 girls), where xerophthalmia and keratomalacia are rife, than around Mwanza where these severe lesions have not been seen (six cases in 33I boys, and none in I 4 girls). It may be concluded that, though Bitot's spots are found only in populations where malnutrition occurs, there is insufficient evidence to attribute them specifically to a deficiency of vitamin $\mathrm{A}$.

\section{Discrete colliquative keratitis}

The condition to which I have given this name, which seems to me to describe its salient features, was originally called 'malnutritional keratitis' by Blumenthal (1950) in South Africa and cases have subsequently been seen by me in East Africa and by Dr F. C. Rodger on the West Coast. As far as I know it has been described to date only in the African. I do not favour the term 'malnutritional keratitis' for the simple reason that malnutrition has not been definitely shown to play a part in its aetiology, unless some new and convincing evidence has been brought forward at this Symposium. It is true that $\mathbf{I}$ have seen it in malnourished children, but in my experience it may also occur in well-nourished children and $I$ have seen an example in an otherwise healthy young adult. I further believe that the only distinctly new condition which Blumenthal has described is that which he has termed 'spontaneous or clean iris prolapse.' His other stages might be the late results of such 
conditions as trachoma, trauma, and purulent infections. Here I deal exclusively with the acute condition of the cornea in which a small area of softening has occurred and in the most advanced stage of which a knuckle of iris has protruded.

One eye is usually more affected than the other, and in the least affected eye it has been possible to demonstrate by the slit lamp that the lesion usually begins in the endothelium of the cornea, the appearance resembling that seen in Fuch's endothelial dystrophy.

I have had the opportunity to study eight cases in all so far; six in Tanganyika, one in Kenya and one in Ethiopia. In addition I have seen very many cases that might at one time have been of this condition but which have healed leaving a leucoma adherens and the aetiology of which cannot be elucidated at this late stage.

Finally, I have a piece of evidence to bring forward which is incomplete but of some interest. All my cases in Mwanza have been seen within a week or two of their onset and they have all occurred during the wet season, which extends usually from October to April. Although vegetables and fruit are plentiful during most of this time the main staples of this area, maize and millet, only become available towards the end.

\section{Refraction and nutrition}

Almost nothing is known about the refractive state of malnourished communities. Pendse (I954) in India showed that the refraction of 'Brahmin' and 'untouchable' children differed markedly, the refraction of the 'untouchables' being more myopic. No conclusion could be drawn as to the role of genetics and environment. Space allows for only a brief reference to new work on this subject undertaken in Tanganyika.

I examined the refraction of primary schoolchildren in two areas, the arid plains of Central Province (Mvumi) and near the shores of Lake Victoria (rural Mwanza). The conditions under which the examinations were made were those observed by Pendse and analysis of the results by his method gave mean values at all ages in both Mwanza and Mvumi approaching those for his 'untouchables'.

Pendse's method of taking the lower hypermetropic axis did not bring out in my observations the gradual trend towards myopia with increasing age during childhood, but if the mean spherical error for the two eyes is used this trend is evident in the Mvumi results and may not appear in those from Mwanza because of the smaller numbers. Fig. I shows the frequency distributions of refraction expressed as percentages. The scatter is much greater in the Mvumi values; there were no refractions higher than +1.5 or -2.5 in Mwanza, and the skewness of the Mwanza material is seen to be slightly greater to the myopic side.

Finally, the findings for the two places also differ markedly when the incidences of mixed astigmatism and anisometropia are compared. Mixed astigmatism was regarded as present when I dioptre or more of difference occurred between the values for the vertical and horizontal axes of the same eye. Anisometropia was taken as present when there was I dioptre or more of difference between the two values for the same axis of the two eyes. Cases in which corneal disease was responsible for 


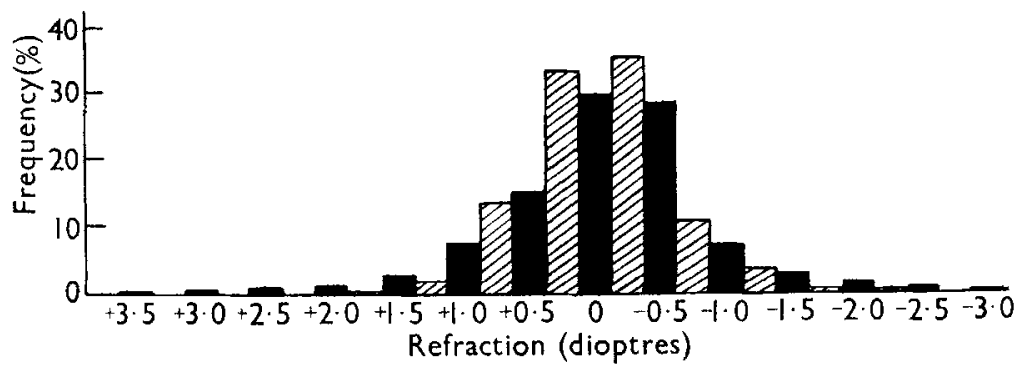

Fig I. Frequency distribution of refraction in schoolchildren in two districts of Tanganyika. Shaded areas, Mwanza; black areas, Mvumi.

refractive error have been excluded. Marked anisometropia was nearly always associated with squint. Nearly $10 \%$ of the Mvumi children had squint. Table I shows the incidences of mixed astigmatism and anisometropia expressed as percentages of the total numbers examined. The values for Mvumi are seen to be very much higher than those for Mwanza.

Table 1 . Incidence of mixed astigmatism and anisometropia in schoolchildren in two districts in Tanganyika

$\begin{array}{lcc} & \text { Mwanza } & \text { Mvumi } \\ & (\%) & (\%) \\ \text { Mixed astigmatism } & 1 \cdot 8 & 12 \cdot 9 \\ \text { Anisometropia } & 2 \cdot 9 & 15 \cdot 8 \\ \quad \text { Total examined } & 438 & 916\end{array}$

It is quite clear that in the more poorly nourished children in Mvumi the incidence of 'irregular' refractions is very high indeed. It may possibly be a reflection of irregularity of general growth and development during the critical early stages of life due to malnutrition, but more work is needed to establish this explanation.

\section{Nutritional amblyopia}

This important cause of blindness in the tropics has been studied especially in the West Indies and West Africa and in Far East P.o.W. camps during the second world war. It seems to have aroused little interest in East Africa, but I have seen a number of cases in Mwanza and from inquiries $I$ have made I gather that they are not at all uncommon. Thiamine therapy in my experience has not given good results, but two cases recently treated with $50 \mu \mathrm{g}$ cyanocobalamin given intramuscularly daily for 4 days and thereafter twice weekly showed dramatic improvement in visual acuity. The response to cyanocobalamin is of special interest in view of the good results claimed for it in the similar condition of tobacco-alcohol amblyopia (Heaton, McCormick \& Freeman, I958).

\section{REFERENCES}

Blumenthal, C. J. (1950). S. Afr. med. F. 24, x91.

Heaton, J. M., McCormick, A. J. A. \& Freeman, A. G. (1958). Lancet, ii, 286.

McKenzie, A. (1939). Trans. R. Soc. trop. Med. Hyg. 32, 717

Pendse, G. S. (1954). Indian med. Res. Mem. no. $3^{8}$. 